\title{
Task Context Effects in Bilingual Nonword Processing
}

\author{
Kristin Lemhöfer ${ }^{1}$ and Ralph Radach ${ }^{2}$ \\ ${ }^{1}$ Radboud University Nijmegen, The Netherlands \\ ${ }^{2}$ Florida State University, Tallahassee, FL
}

\begin{abstract}
To investigate the language-specific or language-integrated nature of bilingual lexical processing in different task contexts, we studied how bilinguals process nonwords that differ in their relative resemblance to the bilinguals' two languages in different versions of the lexical decision task. Unbalanced German-English bilinguals performed a pure-German, a pure-English, and a mixed lexical decision task on the same set of nonwords that were either very English-like or very German-like. Rejection latencies for these two nonword categories were reversed in the pure-English and pure-German conditions: Nonwords that were more similar to the current target language were rejected more slowly. In the mixed task, reaction times were generally slower, and nonwords resembling the participants' subdominant language (English) were harder to reject. The results suggest that task context substantially alters the criteria for the word/nonword decision in bilinguals.
\end{abstract}

Keywords: bilingual lexical access, nonwords, lexical decision, language membership coding

Investigating how people read and process nonwords has proven to be a powerful tool for the understanding of the structure and function of the mental lexicon. Therefore, most models on visual word recognition include accounts of how nonwords are processed in tasks such as naming (Coltheart, Rastle, Perry, Langdon, \& Ziegler, 2001; Seidenberg \& McClelland, 1989; Zorzi, Houghton, \& Butterworth, 1998) or lexical decision (Forster, 1976; Grainger \& Jacobs, 1996; Seidenberg \& McClelland, 1989), and experimental data on nonwords can be used to evaluate these models. However, in the area of bilingual word recognition, very little research has been conducted on how nonwords are processed, even though such data are potentially informative with respect to the bilingual word recognition system. The approach we took is based on the classical finding that in a lexical decision task, nonwords are rejected the faster the less wordlike they are (Coltheart, Davelaar, Jonasson, \& Besner, 1977; Forster \& Shen, 1996). Applied to the bilingual situation, the question arises as to which wordlikeness is relevant to a bilingual, that is, whether it is based on both languages or on only one, and whether this can change depending on the language context of the current situation or task.

The (monolingual) wordlikeness effect for nonwords, as mentioned above, is explained by the influential Multiple Read Out Model (MROM; Grainger \& Jacobs, 1996), an interactive-activation type model, in terms of global lexical activation (see also Jacobs, Graf, \& Kinder, 2003). The more wordlike a nonword is, the more word representations (e.g., orthographic neighbors) it will activate. A high level of lexical activity will subsequently delay the temporal deadline at which the search for a matching word candidate is given up and a "no" response is given. However, the model does not deal with the possibility of words from different languages in the lexicon and their role during lexical access. Applying the model to the bilingual case raises the issue whether the two languages within the bilingual lexicon are functionally separate or integrated: Is it the global lexical activation in both languages (i.e., global wordlikeness) that determines nonword rejection latencies, or is it the activation in the currently relevant language only (i.e., language-specific wordlikeness)? Thus, investigating bilingual nonword processing can contribute to the long-standing debate whether bilingual lexical access is independent of language (or language nonselective), or whether it selectively involves the currently relevant language only.

The currently prevailing view of bilingual lexical access is that it is nonselective with respect to language (de Groot, Delmaar, \& Lupker, 2000; Duyck, van Assche, Drieghe, \& Hartsuiker, 2007; Gollan \& Kroll, 2001; Kerkhofs, Dijkstra, Chwilla, \& de Bruijn, 2006), that is, word candidates from both languages are activated in the lexicon upon presentation of a letter string, even in a situation where only one language is relevant. However, many studies indicate at least some degree of language-specific processing in bilinguals, when triggered by the situational context (de Groot et al., 2000; Dijkstra, de Bruijn, Schriefers, \& ten Brinke, 2000; Dijkstra, van Jaarsveld, \& ten Brinke, 1998; Elston-Güttler, Gunter, \& Kotz, 2005; Gerard \& Scarborough, 1989; Scarborough, Gerard, \& Cortese, 1984). The currently available models on bilingual word recognition (Dijkstra \& van Heuven, 1998, 2002; Grosjean, 1997) differ with respect to the locus and assumed mechanisms of language-specific effects. However, none of these models makes precise predictions on how (and whether), in a given task context, lexical activation in the two languages is combined during the rejection of a nonword.

To investigate this issue, we selected nonwords differing in their relative resemblance to the two languages in question, and used them in different versions of the lexical decision task. Unbalanced German-English bilinguals carried out an English, a German, and a mixed English-German 
Table 1. Characteristics of English-like and German-like nonwords

\begin{tabular}{lcc}
\hline & English-like nonwords & German-like nonwords \\
\hline Example & REATHER & BRASCHE \\
Word length & $6.0(0.8)$ & $6.0(0.8)$ \\
Median rating for wordlikeness in English & $4.1(0.6)$ & $1.8(0.6)$ \\
Median rating for wordlikeness in German & $1.7(0.7)$ & $3.8(0.6)$ \\
Mean number of orthographic neighbors in English & $4.9(2.1)$ & $0.9(1.1)$ \\
Mean number of orthographic neighbors in German & $0.4(0.8)$ & $4.4(2.4)$ \\
Mean summed frequency of neighbors in English & $221(320)$ & $13(30)$ \\
Mean summed frequency of neighbors in German & $16(61)$ & $954(2788)$ \\
Mean positional bigram frequency in English & $5173(2625)$ & $4252(2031)$ \\
Mean positional bigram frequency in German & $3249(2007)$ & $8296(4708)$ \\
\hline
\end{tabular}

Note. All calculations are based on 5-7 letter lemmas with a frequency above 0. Standard deviations are given in parentheses.

${ }^{a}$ The larger numbers for German nonwords result from a few German-like stimuli (habel, werlen, wernen, wersen) that are neighbors to the extremely high-frequent German auxiliary verbs haben ("to have") and werden ("to become", but also "will" and passive voice auxiliary verb). However, these high-frequency neighbors apparently did not lead to a higher perceived level of wordlikeness, as revealed in the wordlikeness ratings.

lexical decision task including "English-like" and "Germanlike" nonwords.

If nonword rejection is based on the amount of global lexical activation independent of language membership and situational context, the pattern of reaction times (RTs) for the different types of nonwords should remain constant across the three different tasks. On the other hand, a language-exclusive context might lead to the prioritization of the target language above the other during lexical access, in which case "English-like" nonwords should be rejected with more difficulty in an English context (where English words may be "prioritized") than in a German context and vice versa, with the pattern in the mixed, languageneutral context in between the two.

In fact, the mixed-language context provides another interesting possibility to test the nonselective view. Given that the bilingual participants in this study were less proficient in English (their second language) than in German, English-like nonwords should - across both languages cause less global lexical activity than German-like nonwords, due to their reduced subjective frequency. According to the MROM account, this reduced lexical activity (making the English-like nonwords less wordlike in a general sense) should lead to faster rejection latencies, if German- and English-like stimuli are treated equally. However, this is opposite to what has been observed by Lemhöfer and Dijkstra (2004) for unbalanced Dutch-English bilinguals in a mixed-language lexical decision task: English-like nonwords were rejected more slowly than Dutch-like ones. Whether this result can be replicated for German-English bilinguals, and how the pattern in the mixed task compares to the two pure-language tasks, remains to be investigated.

\section{Method}

\section{Participants}

Twenty-three German-English bilinguals participated, most of whom were students of English at RWTH Aachen
University and had lived in an English-speaking country for at least six months. Three of them had acquired English early in life, the remaining participants had learned English at school from the age of 10 . They reported to use of English regularly, with German being their dominant language. An English and a German language test, taken from materials used by official German institutions for adult education, were carried out by the participants at the beginning of the respective (English or German) session. Both were multiple choice tests consisting of 46 items each, and addressed subtleties in word meaning and grammatical constructions on a high level of difficulty.

Five participants were excluded from the analyses because of too many errors in the English test. The remaining 18 participants were between 19 and 36 years old (mean 27.5), seven of them male and eleven female. They obtained a mean score of 40.3 (out of 46) correct responses in the English test, and of 45.1 in the German test, confirming their language dominance in German. All participants reported to have normal or corrected-to-normal vision.

\section{Materials}

The nonwords (listed in the Appendix) originated from English or German words taken from the CELEX database (Baayen, Piepenbrock, \& Gulikers, 1995) in which one letter had been changed. All nonwords were orthographically legal in both English and German, as indicated by position-specific bi- and trigram frequencies above zero, and ranged between five and seven letters in length. Measures of orthographic neighborhood (Coltheart et al., 1977) were used to select nonwords that had a higher overall lexical similarity to English versus German or vice versa. The neighborhood characteristics as well as bigram frequency for the two classes of nonwords are given in Table 1. Item selection was completed on the basis of a rating study conducted with 16 native speakers of English and German, respectively, in which the nonwords were rated according to how plausible they were as words of English or German (the raters' native language) on a five-point scale. On the basis of 
this study, 100 English-like and 100 German-like nonwords were finally selected that had been rated as plausible (as indicated by the median rating) in the language they were supposed to resemble, and as implausible in the other language.

Out of the 100 nonwords of each category (English- or German-like), 50 were randomly selected to appear in all three context conditions; the other 50 were used as filler nonwords in the mixed-language condition only, which consisted of twice as many word and nonword stimuli. The mean medians of ratings for the 100 selected nonwords (excluding fillers) are also given in Table 1. The group of English nonwords had higher median ratings, mean positional bigram frequencies, and a higher number and summed frequency of orthographic neighbors in English than the German nonwords, and vice versa, as verified by one-tailed unpaired $t$ tests (all $p<.03$ ).

Besides the nonword stimuli, the experimental lists contained an equal number of words (100 in the pure-language conditions, and 200 in the mixed-language condition). These were 100 English and 100 German verbs, nouns, and adjectives selected from the CELEX database with a word length between five and seven letters, and from a large frequency range (1-876 occurrences per million, mean 75). German and English words were matched for word frequency, word length, and syntactic category. In analogy to the nonwords, all words were orthographically legal in both English and German, that is, all bi- and trigram frequencies were above zero for both languages. No word forms that exist in both English and German were used.

\section{Procedure and Apparatus}

The three different versions of the lexical decision task (German, English, or mixed-language lexical decision) were carried out on separate days, with approximately one week between the sessions, by the same group of participants. The order of the three sessions was counterbalanced, that is, each of the six possible orders of the three task conditions was assigned to three participants. At the beginning of each session, a language test was given in the language(s) relevant to the experimental task to follow (German, English, or both). The tests were intended both to assess the participant's proficiency, especially in English, and to preactivate the relevant language(s) as much as possible. The English and the German tests have already been described above (under "participants"). The bilingual "test" was used mainly in order to adhere to the general structure of the experimental sessions, beginning with a proficiency test, and to emphasize the bilingual character of the mixedlanguage session. It was a multiple choice test with 26 items constructed by the first author testing for knowledge about English and German proverbs and sayings. The results of this test were not analyzed in any way. During purelanguage sessions, only the relevant language was spoken between the participant and the experimenter.
For the lexical decision task, the critical set of nonwords was identical across the three sessions; in the mixedlanguage condition, the filler nonwords were added to equal the doubled number of word items. The word stimuli included either the German word set (in the German lexical decision task), the English word set (in the English task), or both (in the generalized lexical decision task). In each session, participants were instructed to decide as quickly and accurately as possible whether the presented letter string constituted a word in the given language(s) or not by pressing one of two buttons. They were explicitly told whether the stimulus lists in the lexical decision task would contain words in German, English, or both.

The total number of stimuli was 200 in the purelanguage sessions and 400 in the mixed-language task, consisting of $50 \%$ nonwords and words, respectively. The sessions were split into blocks of 100 stimuli, between which participants could take breaks. Additionally, the first four stimuli of each block were buffer items that were not included in the analyses. At the beginning of each session, a training block of 40 items was presented. Each participant was randomly assigned to one of four fixed orders of stimulus presentation. These lists had been created pseudorandomly, with the restriction that no more than three words or nonwords occurred in a row.

The stimuli were presented in upper case ${ }^{1}$ and in black print (type Courier) against a light gray background, shown on a 15 -in. monitor with a standard VGA-resolution. The experiment was controlled by software developed by the Technical Group of the Aachen University Psychology Department. At the start of each trial, a fixation cross was presented for $700 \mathrm{~ms}$. $150 \mathrm{~ms}$ after the cross had disappeared from the screen, the letter string was shown until the participant responded by pressing one of the two response buttons, or until a time-out of $5,000 \mathrm{~ms}$ had passed. The intertrial interval was $600 \mathrm{~ms}$. The responses and RTs were recorded with millisecond resolution.

\section{Results}

\section{Nonwords}

For the analysis of nonword responses, only those nonwords that had occurred in all three context conditions were included.

For the analysis of RTs, only correct responses were considered (92.8\% of the data). Furthermore, RTs in correct trials that were classified as outliers (those that fell outside a range of two standard deviations from both the participant and item mean; $1.7 \%$ of the correct trials) were excluded. RTs and error rates (ERs) were analyzed in repeated measures ANOVAs with Context (English, German, and Mixed) and Nonword Category (English-like vs. German-like) as factors. Context was a within-participants and within-items factor, while Nonword Category was a within-participants, but

1 In German, case is a cue for syntactic class (nouns are written in capitals), which is why we used upper case only. 
Table 2. Mean RTs (in ms) and error rates (ERs; in \%) for nonwords in all task conditions

\begin{tabular}{|c|c|c|c|c|c|c|}
\hline & \multicolumn{2}{|c|}{ English task } & \multicolumn{2}{|c|}{ German task } & \multicolumn{2}{|c|}{ Mixed task } \\
\hline & RT & ER & RT & ER & RT & ER \\
\hline German-like nonwords & $707(61)$ & $1.1(2.1)$ & $774(143)$ & $2.6(2.5)$ & $860(170)$ & $3.4(3.7)$ \\
\hline English-like nonwords & $822(115)$ & $16.2(10.4)$ & 717 (116) & $1.0(1.6)$ & $915(175)$ & $18.9(13.2)$ \\
\hline
\end{tabular}

Note. Standard deviations are given in parentheses.

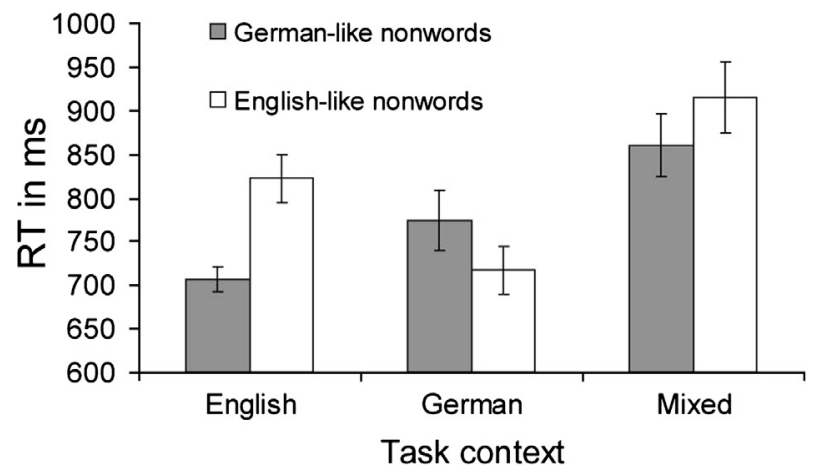

Figure 1. Mean reaction times for English-like and German-like nonwords in the three task conditions.

between-items factor. The mean RTs and ERs for all nonword and context conditions are shown in Table 2 .

\section{RTs}

Figure 1 gives an illustration of the pattern of RTs. The analysis showed a significant effect of Context $\left(F_{1}(2,34)=15.65, \quad p<.001, \quad \eta_{\mathrm{p}}{ }^{2}=.48 ; \quad F_{2}(2,196)=\right.$ $\left.130.50, p<.001, \eta_{\mathrm{p}}{ }^{2}=.57\right)$ : Nonwords were responded to fastest in the German context (745 ms), less fast in the English context (764 ms) and most slowly in the mixed context (888 ms). Planned comparisons revealed that the difference between the German and the English context was significant across items $\left(F_{2}(1,98)=7.24, p<.01, \eta_{\mathrm{p}}{ }^{2}=\right.$ $.07)$, but not across participants $\left(F_{1}<1\right)$. However, the difference between the mixed and the English context was significant in both analyses $\left(F_{1}(1,17)=19.74, p<.001\right.$, $\left.\eta_{\mathrm{p}}{ }^{2}=.54 ; F_{2}(1,98)=201.4, p<.001, \eta_{\mathrm{p}}{ }^{2}=.67\right)$. Nonword Category also exerted a significant effect on RTs $\left(F_{1}(1,17)=15.04, p<.01, \eta_{\mathrm{p}}{ }^{2}=.47 ; F_{2}(1,98)=7.77\right.$, $\left.p<.01, \eta_{\mathrm{p}}{ }^{2}=.07\right)$, with faster RTs to German-like (780 ms) than to English-like nonwords (818 ms).

Most importantly, however, there was an interaction of Context and Nonword Category $\left(F_{1}(2,34)=34.82\right.$, $p<.001, \eta_{\mathrm{p}}{ }^{2}=.67 ; F_{2}(2,196)=42.91, p<.001, \eta_{\mathrm{p}}{ }^{2}=$ $.31)$. In particular, German-like nonwords were rejected more slowly in the German as opposed to the English context (as confirmed by planned comparisons: $F_{1}(1,17)=7.23, \quad p<.05, \eta_{\mathrm{p}}{ }^{2}=.30 ; \quad F_{2}(1,49)=33.53$, $\left.p<.001, \eta_{\mathrm{p}}{ }^{2}=.41\right)$, while the opposite was true for
English-like nonwords $\left(F_{1}(1,17)=13.67, p<.01, \eta_{\mathrm{p}}{ }^{2}=\right.$ $\left..45 ; F_{2}(1,49)=67.84, p<.001, \eta_{\mathrm{p}}{ }^{2}=.58\right)$. Both categories of nonwords were responded to most slowly in the mixed-language context, as verified by planned comparisons between the slower of the two pure-language contexts and the mixed context (German-like nonwords: $F_{1}(1,17)=$ $7.76, p<.05, \eta_{\mathrm{p}}{ }^{2}=.31 ; F_{2}(1,49)=50.32, p<.001, \eta_{\mathrm{p}}{ }^{2}=$ .51 ; English-like nonwords: $F_{1}(1,17)=7.73, p<.05$, $\left.\eta_{\mathrm{p}}{ }^{2}=.31 ; F_{2}(1,49)=52.28, p<.001, \eta_{\mathrm{p}}{ }^{2}=.52\right)$. Further planned comparisons indicated that in the mixed context, English-like nonwords were responded to more slowly than German-like nonwords $\left(F_{1}(1,17)=22.24, p<.001, \eta_{\mathrm{p}}{ }^{2}=\right.$ $\left..57 ; F_{2}(1,98)=9.45, p<.01, \eta_{\mathrm{p}}^{2}=.09\right)$.

\section{ERs}

The results of the analysis of ERs paralleled those for RTs. Context had a main effect $\left(F_{1}(2,34)=23.98, p<.001\right.$, $\left.\eta_{\mathrm{p}}{ }^{2}=.59 ; F_{2}(2,196)=34.04, p<.001, \eta_{\mathrm{p}}{ }^{2}=.26\right)$, with most errors in the mixed context $(11.2 \%)$, least errors in the German context $(1.8 \%)$, and the English context in between the two $(8.7 \%)$. The difference between the two pure-language contexts was significant $\left(F_{1}(1,17)=28.71\right.$, $p<.001, \eta_{\mathrm{p}}{ }^{2}=.63 ; F_{2}(1,98)=25.75, p<.001, \eta_{\mathrm{p}}{ }^{2}=$ $.21)$, as was the difference between the English and the mixed context $\left(F_{1}(1,17)=4.34, p=.053, \quad \eta_{\mathrm{p}}{ }^{2}=.20\right.$; $\left.F_{2}(1,98)=9.08, p<.01, M S E=0.09\right)$. Furthermore, there was a significant effect of Nonword Category, with more errors on English-like (12.0\%) than on German-like nonwords $\left(2.4 \% ; \quad F_{1}(1,17)=38.65, \quad p<.001, \quad \eta_{\mathrm{p}}{ }^{2}=.70\right.$; $\left.F_{2}(1,98)=25.57, p<.01, \eta_{\mathrm{p}}{ }^{2}=.21\right)$.

Again, Context significantly interacted with Nonword Category $\left(F_{1}(2,34)=33.44, p<.001, \eta_{\mathrm{p}}{ }^{2}=.66 ; F_{2}(2,196)=\right.$ $\left.34.01, p<.001, \eta_{\mathrm{p}}{ }^{2}=.26\right)$. Planned comparisons indicated that German-like nonwords were responded to somewhat more accurately in the English relative to the German context, even though this difference did not reach significance in the analysis across items $\left(F_{1}(1,17)=4.48, \quad p<.05, \quad \eta_{\mathrm{p}}{ }^{2}=.21\right.$; $\left.F_{2}(1,49)=2.13, p=.15\right)$. Reponses on English-like nonwords, however, were more accurate in the German than in the English context $\left(F_{1}(1,17)=38.35, p<.001, \eta_{\mathrm{p}}{ }^{2}=.69\right.$; $\left.F_{2}(1,49)=36.24, p<.001, \eta_{\mathrm{p}}{ }^{2}=.43\right)$. This time, for both nonword types, the accuracy in the mixed context was not significantly lower than in the least accurate of the two purelanguage contexts (all $p>.15$ apart from the item analysis for English-like nonwords, with $p<.05$ ). However, in this context, English-like nonwords evoked more errors than German-like nonwords $\left(F_{1}(1,17)=33.44, p<.001, \eta_{\mathrm{p}}{ }^{2}=\right.$ $\left..66 ; F_{2}(1,98)=29.32, p<.001, \eta_{\mathrm{p}}{ }^{2}=.23\right)$.

(C) 2009 Hogrefe \& Huber Publishers 
Table 3. Mean RTs (in ms) and error rates (ERs; in \%) for words in all context conditions

\begin{tabular}{|c|c|c|c|c|}
\hline & \multicolumn{2}{|c|}{ Pure-language tasks } & \multicolumn{2}{|c|}{ Mixed-language tasks } \\
\hline & RT & ER & RT & ER \\
\hline German words & 655 (117) & $2.7(2.0)$ & $679(95)$ & $2.8(2.3)$ \\
\hline English words & $684(76)$ & $8.0(4.7)$ & $741(112)$ & $8.0(5.3)$ \\
\hline
\end{tabular}

Note. Standard deviations are given in parentheses.

\section{Words}

The RTs and ERs for words are shown in Table 3. We tested the effect of Context on word RTs and ERs in 2 (Context) $\times 2$ (Language) repeated measures ANOVAs. RTs in the mixed context were longer $(710 \mathrm{~ms})$ than in the respective pure-language context $(667 \mathrm{~ms}$; $F_{1}(1,17)=8.22, p<.05, \eta_{\mathrm{p}}{ }^{2}=.33 ; F_{2}(1,198)=67.29$, $\left.p<.001, \eta_{\mathrm{p}}{ }^{2}=.25\right)$, while there was no significant effect of Context on ERs (both $F<1$ ). Not surprisingly, German words were generally reacted to faster $\left(F_{1}(1,17)=8.52\right.$, $\left.p<.05, \eta_{\mathrm{p}}{ }^{2}=.33 ; F_{2}(1,198)=17.17, p<.001, \eta_{\mathrm{p}}{ }^{2}=.08\right)$ and more accurately than English words $\left(F_{1}(1,17)=21.12\right.$, $p<.001, \eta_{\mathrm{p}}{ }^{2}=.55 ; F_{2}(1,198)=13.68, p<.001, \eta_{\mathrm{p}}{ }^{2}=$ $.07)$. The interaction of Language and Context was nonsignificant (all $p>.20$ ) apart from in the item-analysis of RTs $\left(F_{2}(1,198)=9.55, p<.01, \eta_{\mathrm{p}}^{2}=.05\right)$.

\section{Discussion}

The context-sensitivity of nonword processing in bilinguals was investigated by using two kinds of nonwords (Englishlike and German-like) in three task conditions (English, German, and English-German lexical decision). The results show that the data pattern for nonwords completely reversed in the two pure-language contexts: English-like nonwords were more difficult to reject in the English relative to the German task, while the opposite was true for the Germanlike nonwords. In the mixed task, response times were generally slower; additionally, in this context, responses to English-like nonwords were slower and less accurate than that to German-like ones.

The observation that identical stimuli produced completely opposite RT patterns in different language and task contexts shows that bilinguals do not base their nonword decision on language- and context-independent criteria, for example on the overall lexical activation, as a strict nonselective view of bilingual access would predict. Rather, in the pure-language contexts, stimulus similarity to the relevant and nonrelevant language is clearly discriminated in the course of lexical access, suggesting a language-selective way of processing.

Turning back to the MROM (Grainger \& Jacobs, 1996) that offers the most explicit account on nonword rejection in lexical decision, it is possible to adapt the model in a way that accommodates the present major findings. As already mentioned, the model explains longer RTs for more wordlike nonwords with an extension of the temporal deadline at which a "no" response is given when initial lexical activity is high. Our data show that in the bilingual case, a difference must be made between the lexical activation in the relevant language and that in the irrelevant one (in the pure-language conditions). Thus, in the English lexical decision task, it is the activation of English words that is the primary determinant of the temporal deadline, while the opposite is the case for the German task. This might be achieved, for instance, by a simple weighting of languages in the lexicon (e.g., lexical activations in the relevant language are multiplied by a certain factor). The original Bilingual Interactive Activation (BIA) model (Dijkstra \& van Heuven, 1998) provides such an account by proposing the existence of language nodes. These nodes are activated by word representations from the respective language, thus serving as language membership representations (or "language tags"). Moreover, they feed activation back to the word level by selectively inhibiting words from the other language, thereby effectively functioning as language filters. This model can account for the present data, at least as far as the two pure-language conditions are concerned: In these conditions, the relevant language node is activated by the word trials, and possibly also by the task instruction. It then selectively inhibits words from the nontarget language. When a nonword resembling the nontarget language is subsequently encountered, it will cause only very little activation, making it easy to reject it. Note that in the extended BIA+ model (Dijkstra \& van Heuven, 2002), the notion of "language filtering" by the language nodes is dropped and replaced by more complicated post-lexical, "task level" mechanisms responsible for languageselective effects.

While the data pattern in the two pure-language contexts is fairly easily explainable by this BIA-type account, the data pattern in the mixed contexts is somewhat more puzzling. In this context, RTs were generally slower compared to the two pure-language tasks, not only for nonwords, but also for words. These results replicate the "classical" finding that there is a cost associated with the simultaneous processing of two languages (Kolers, 1966; Macnamara \& Kushnir, 1971), just as the mixing of any kind of stimulus categories typically produces a cost in RT experiments (for overviews, see Los, 1999; Lupker, Kinoshita, Coltheart, \& Taylor, 2003). In particular, language switch costs in lexical decision have repeatedly been observed before (Grainger \& Beauvillain, 1987; Thomas \& Allport, 2000; von Studnitz \& Green, 1997). If, as claimed by the nonselective view of bilingual lexical access, both languages are always co-activated in the mental lexicon, this finding of "mixed-language costs" is difficult 
to explain. The original BIA model (Dijkstra \& van Heuven, 1998) explains language switch costs in lexical terms, by way of top-down inhibition by language nodes. In "task schema" terms, the costs of processing two languages at a time are regarded as switch costs between two different task schemas ("recognizing English words" and "recognizing German words"), and are therefore thought to originate from outside the mental lexicon (Green, 1998). Note that this task schema account is similar to the "alternate processing" account of mixing costs in other experimental paradigms, according to which switching between different cognitive processes takes time (Los, 1999). However, the question remains why there can be no single task schema (or cognitive process) for recognizing words from both languages, especially when the bilingual lexicon is assumed to be integrated across languages (Thomas \& Allport, 2000). Wherever the locus of the effect is, the data show once again that the bilingual word recognition system benefits from the narrowing of the lexical search space, as it is the case in the pure-language contexts.

A second observation in the mixed-language condition was that participants took longer and made more errors when rejecting English-like nonwords relative to Germanlike ones. An analogous result has been obtained by Lemhöfer and Dijkstra (2004) with Dutch (L1) and English (L2). It seems clear that the difference between the two nonword categories is a consequence of the participants' language dominance, since the mixed-language context itself does not prioritize any of the languages. While it does not come as a surprise that discriminating between real words and very wordlike nonwords is more difficult in a less proficient language, explaining this finding with a language nonselective approach of bilingual lexical access is difficult. When assuming that in a language-neutral situation, unbalanced bilinguals activate their first language more than L2 (Grosjean, 2001), English-like nonwords should for our population cause lower global activation levels when compared to German-like nonwords. This means that in terms of lexical activation, English-like nonwords should behave as less wordlike and should therefore be rejected faster than German-like nonwords, at least if the same recognition and rejection criteria are applied. The fact that the opposite was the case shows that English- and German-like stimuli must be treated differently during the word recognition process. In particular, when stimuli resemble the weaker language, the decision process may simply be given more time (i.e., temporal deadlines are set later), taking the slower rise of L2 word activations into account (see also Lemhöfer \& Dijkstra, 2004).

To summarize the present findings, the rejection latencies and ERs for nonwords showed a large degree of context-sensitivity: The same set of stimuli was processed differently, depending on the language and task context. In pure-language tasks, nonwords that were similar to the nonrelevant rather than the relevant language could be rejected very quickly, which indicates that the rejection criteria for nonwords are altered by the language context. These findings suggest that lexical access is to a certain degree language-selective. In the mixed (and thus language-neutral) context, there was also evidence for the operation of different recognition and rejection criteria for the two classes of nonwords, with generally slower decisions for stimuli requiring a decision in the weaker language, English.

This study demonstrates that the investigation of nonword processing is a useful tool for the study of bilingual lexical organization, and provides valuable extensions of current concepts and models of visual word recognition in bilinguals, in particular, with respect to the limits of nonselectivity during lexical access.

\section{Acknowledgements}

The research was conducted as part of a Master's Thesis while both authors were at the Psychology Department of RWTH Aachen University, Germany. We would like to thank Dr. Peter H. Marsden at the English Department of RWTH Aachen University for his help in finding bilingual participants.

\section{References}

Baayen, R. H., Piepenbrock, R., \& Gulikers, L. (1995). The CELEX lexical database (Release 2), [CD-ROM]. Philadelphia, PA: Linguistic Data Consortium, University of Pennsylvania [Distributor].

Coltheart, M., Davelaar, E., Jonasson, J. T., \& Besner, D. (1977). Access to the internal lexicon. In S. Dornic (Ed.), Attention and performance VI (pp. 535-555). Hillsdale, NJ: Lawrence Erlbaum.

Coltheart, M., Rastle, K., Perry, C., Langdon, R., \& Ziegler, J. (2001). DRC: A dual route cascaded model of visual word recognition and reading aloud. Psychological Review, 108(1), 204-256.

de Groot, A. M. B., Delmaar, P., \& Lupker, S. J. (2000). The processing of interlexical homographs in translation recognition and lexical decision: Support for nonselective access to bilingual memory. Quarterly Journal of Experimental Psychology, 53A(2), 397-428.

Dijkstra, T., de Bruijn, E., Schriefers, H., \& ten Brinke, S. (2000). More on interlingual homograph recognition: Language intermixing versus explicitness of instruction. Bilingualism: Language and Cognition, 3(1), 69-78.

Dijkstra, T., \& van Heuven, W. J. B. (1998). The BIA model and bilingual word recognition. In J. Grainger, \& A. M. Jacobs (Eds.), Localist connectionist approaches to human cognition (pp. 189-225). Mahwah, NJ: Lawrence Erlbaum.

Dijkstra, T., \& van Heuven, W. J. B. (2002). The architecture of the bilingual word recognition system: From identification to decision. Bilingualism: Language and Cognition, 5(3), 175-197.

Dijkstra, T., van Jaarsveld, H., \& ten Brinke, S. (1998). Interlingual homograph recognition: Effects of task demands and language intermixing. Bilingualism: Language and Cognition, 1(1), 51-66.

Duyck, W., van Assche, E., Drieghe, D., \& Hartsuiker, R. J. (2007). Visual word recognition by bilinguals in a sentence context: Evidence for non-selective lexical access. Journal of Experimental Psychology: Learning, Memory, and Cognition, 33(4), 663-679.

Elston-Güttler, K. E., Gunter, T. C., \& Kotz, S. A. (2005). Zooming into L2: Global language context and adjustment 
affect processing of interlingual homographs in sentences. Cognitive Brain Research, 25(1), 57-70.

Forster, K. I. (1976). Accessing the mental lexicon. In R. J. Wales, \& E. W. Walker (Eds.), New approaches to language mechanisms. Amsterdam: North-Holland.

Forster, K. I., \& Shen, D. (1996). No enemies in the neighborhood: Absence of inhibitory neighborhood effects in lexical decision and semantic categorization. Journal of Experimental Psychology: Learning, Memory and Cognition, 22(3), 696-713

Gerard, L. D., \& Scarborough, D. L. (1989). Language-specific lexical access of homographs by bilinguals. Journal of Experimental Psychology: Learning, Memory, and Cognition, 15(2), 305-315.

Gollan, T. H., \& Kroll, J. F. (2001). Bilingual lexical access. In B. Rapp (Ed.), The handbook of cognitive neuropsychology: What deficits reveal about the human mind (pp. 321-345). Philadelphia, PA: Psychology Press.

Grainger, J., \& Beauvillain, C. (1987). Language blocking and lexical access in bilinguals. Quarterly Journal of Experimental Psychology, 39A(2), 295-319.

Grainger, J., \& Jacobs, A. M. (1996). Orthographic processing in visual word recognition: A multiple read-out model. Psychological Review, 103(3), 518-565.

Green, D. W. (1998). Mental control of the bilingual lexicosemantic system. Bilingualism: Language and Cognition, 1(2), 67-81.

Grosjean, F. (1997). Processing mixed language: Issues, findings and models. In A. M. B. de Groot, \& J. F. Kroll (Eds.), Tutorials in bilingualism: Psycholinguistic perspectives (pp. 225-254). Hillsdale, NJ: Lawrence Erlbaum.

Grosjean, F. (2001). The bilingual's language modes. In J. Nicol (Ed.), One mind, two languages: Bilingual language processing (pp. 1-22). Oxford: Blackwell.

Jacobs, A. M., Graf, R., \& Kinder, A. (2003). Receiver operating characteristics in the lexical decision task: Evidence for a simple signal-detection process simulated by the Multiple Read-Out Model. Journal of Experimental Psychology: Learning, Memory, and Cognition, 29(3), 481-488.

Kerkhofs, R., Dijkstra, T., Chwilla, D. J., \& de Bruijn, E. R. A. (2006). Testing a model for bilingual semantic priming with interlingual homographs: RT and N400 effects. Brain Research, 1068(1), 170-183.

Kolers, P. A. (1966). Reading and talking bilingually. American Journal of Psychology, 79(3), 357-376.

Lemhöfer, K., \& Dijkstra, T. (2004). Recognizing cognates and interlexical homographs: Effects of code similarity in language specific and generalized lexical decision. Memory and Cognition, 32(4), 533-550.

Los, S. A. (1999). Identifying stimuli of different perceptual categories in mixed blocks of trials: Evidence for cost in switching between computational processes. Journal of Experimental Psychology: Human Perception and Performance, 25(1), 3-23.

Lupker, S. J., Kinoshita, S., Coltheart, M., \& Taylor, T. E. (2003). Mixing costs and mixing benefits in naming words, pictures, and sums. Journal of Memory and Language, 49(4), 556-575.

Macnamara, J., \& Kushnir, S. L. (1971). Linguistic independence of bilinguals: The input switch. Journal of Verbal Learning and Verbal Behavior, 10(5), 480-487.

Scarborough, D. L., Gerard, L., \& Cortese, C. (1984). Independence of lexical access in bilingual word recognition. Journal of Verbal Learning and Verbal Behavior, 23(1), 84-99.
Seidenberg, M. S., \& McClelland, J. L. (1989). A distributed, developmental model of word recognition and naming. Psychological Review, 96(4), 523-568.

Thomas, M. S. C., \& Allport, A. (2000). Language switching costs in bilingual visual word recognition. Journal of Memory and Language, 43(1), 44-66.

von Studnitz, R. E., \& Green, D. W. (1997). Lexical decision and language switching. International Journal of Bilingualism, $1(1), 3-24$.

Zorzi, M., Houghton, G., \& Butterworth, B. (1998). Two routes or one in reading aloud? A connectionist dual-process model. Journal of Experimental Psychology: Human Perception and Performance, 24(4), 1131-1161.

\section{Appendix}

\section{English-Like Nonwords}

ARONE, BEALER, BINGLE, BOBBLER, CHAFTER, CHALER, CHARN, CHISE, DESPIRE, DEVER, GARDER, GOBBER, GORKER, GOUND, JASTER, LANER, LATTLE, MILLAGE, MOSHER, NATTLE, NULTURE, PANER, PESTURE, PIPPER, POCKER, PONCH, PORSE, RAGGER, REATHER, REVINE, RILER, RITHER, SEEPER, SERRY, SHART, SIGGER, SKATTER, SLATTER, SMUTTER, SOVER, STATCH, STRIBE, TETTLE, TIGGER, TINGER, TRINKLE, TWINDLE, WAPER, WOVER, WRISTLE

\section{German-Like Nonwords}

BATTE, BELLERN, BRASCHE, BUCKERN, DASTEN, DATTE, DIEDER, FEBER, FEUTE, FIEGE, FILDERN, FOLLERN, GORTE, GRAKEN, GRALEN, HABEL, HIEDER, HITTE, JARREN, JASTEN, MAUDERN, VASTEN, NASTEN, NATTEN, NAUCHEN, NEILE, PARREN, PRILLEN, REIGE, REIKERN, REIPE, RUNNEN, RUTTERN, SCHEILE, SELLE, SERICHT, SERTE, SIENE, SPIEGER, WARGEN, WARSEN, WEIFE, WEIGEN, WERLEN, WERNEN, WERSEN, WINGEN, WIRTERN, WRACHT, ZENNEN

Received August 3, 2007

Revision received November 14, 2007

Accepted December 1, 2007

Kristin Lemhöfer

Donders Institute for Brain, Cognition and Behaviour Radboud University Nijmegen

P.O. Box 9104

6500 HE Nijmegen

The Netherlands

Tel. +31 (24) 3612630

Fax +31 (24) 3616066

E-mail k.lemhofer@donders.ru.nl 